\title{
Rectifier Dynamic Electro-Thermal Simulation for Power Factor Correction in Electric Vehicles Application
}

\author{
Moez Ayadi ${ }^{\dagger}$, Moez Ghariani* and Amine Toumi**
}

\begin{abstract}
This paper presents a PFCVF (Power Factor Correction) rectifier that uses a variable frequency source for alternators in electric and hybrid vehicles application. This technique allows to preserve a good THD (Total Harmonic Distortion) of the input source at any frequency and to decrease losses in semiconductors switches, thereby permitting more stability and decreasing the apparent power requirements. A comparative study between the standard and the new technique is made. A thermal network is used to calculate the junction temperatures in order to estimate the equivalent losses in the rectifier with respect of junction temperature modifications and power equilibrium. The relations of the proposed model are defined and simulation results as well as experimental results are discussed.
\end{abstract}

Keywords: Alternator, Converter performance, Harmonic injection, Power factor correction, Threephase rectifier, Electro-thermal model of power diode

\section{Introduction}

Using multi-physics simulation the development process of complex systems such as electric vehicles (EVs) with high power density, can be improved and enhanced. However, the large number of differential equations as well as unequal time constants cause large processing times. In the case of EVs [1] simulations the losses and the energy flow between components can be investigated when electrical and thermal effects are measured. Such simulations useful for cooling systems optimization in the power train. For modeling the losses in rectifiers, efficiency maps for electric drive train components can be used. However, they do not contain information of electrical waveforms in rectifiers. Each model is built with an efficiency map applies to a specific rectifier module. In addition, these maps refer to fixed operation conditions that can be subject to change in a drive cycle. Consequently such models are no suitable for transient thermal simulations.

It can be fulfilled that rectifiers conform to modern standards and have been widely accepted in industry. The simplest line-commutated converters use diodes to transform the electrical energy from AC to DC. The major disadvantage of these commutated converters is the reactive power and the generation of harmonics [2-4]. Harmonics have a bad consequence on electrical systems process. Therfore, increasing attention is paid to their generation and control $[5,6]$. One of the most popular PFC

$\dagger$ Corresponding Author: Dept. of Informatics Industrial (ENETCom),

Sfax Univerity, Tunisia. (moez.ayadi@enis.rnu.tn)

* Dept. of Electronic (ENETCom), Sfax Univerity, Tunisia.

(moez.ghariani@enetcom.rnu.tn)

** Dept. of Electrical (ENIS), Sfax Univerity, Tunisia.

(amine toumi_tn@yahoo.f)

Received: June 8, 2015; Accepted: February 7, 2016
(Power Factor Correction) methods for three-phase input is a full-bridge type pulse with modulation (PWM) rectifier. The conventional PWM rectifier allows obtaining a sinusoidal input current without harmonics distortion. Nevertheless, in regard to cost, the conventional PWM rectifier is not the best solution for the PFC [7-10]. One simple method to reduce input current harmonics is the use of multi-pulse connections based on transformers with multiple windings. An extra improvement is the use of passive power filters. In the last years, active filters were presented to reduce the harmonics injected to the mains supply. A supplementary way of harmonics diminution is the power-factor correction (PFC). Within these converters, controlled power switches like gate-turn-off thyristors (GTOs), insulated gate bipolar transistors (IGBTs), are integrated in the rectifier power circuit to change actively the input current waveform, decreasing the distortion [1116]. These circuits reduce harmonics and improve the power factor. Harmonic currents cause additional Joule losses in conductors. Their presence reduces the lifetime of the alternators and increases their apparent power requirements.

In this paper, we present a Power Factor Correction rectifier (PFCVF) that uses a variable frequency source for alternators for electric and hybrid vehicles application. The proposed electric rectifier model can be parametrized with data sheet information or reasonably low measurement effort. It is useful in multi-physics simulations in the purpose of calculation of currents averaged waveforms, voltages and losses in individual semiconductors with respect of junction temperature modifications and power equilibrium. This solution aims to improve stability, minimize losses and reduce alternator apparent power requirements for the sake of a better design, better performance and lower cost. Firstly, we present the 
synchronous alternator model. In the second section, we describe the third harmonic injection method. As we use a tuned circuit in this injection method, a fixed frequency current injection is applied which is useful only at a fixed frequency source. A new part in the injection method is presented. It generates a sine wave current for injection and can modify the amplitude, the frequency and even the form of the injected signal. The new designed circuit works at a large frequency range of the input source. In the third section, the model of electro thermal power diode is proposed. Finally, simulations and experimental results are discussed to highlight the effectiveness of the new design.

\section{Third harmonic Current Injection Description}

The gaps in the phase currents are the main reason for introducing the current injection methods. Since one phase voltage cannot be the highest and the lowest at the same time for the given set of phase voltages, two of the phases are connected to the load while one phase is unconnected in each point in time. This results in an input current equal to zero in the time interval when the phase voltage is neither maximal nor minimal. Moreover, three-phase diode bridge rectifier suffers from relatively high total harmonic distortion (THD) in the input currents that can be reduced using the injection method. Carried out simulation results

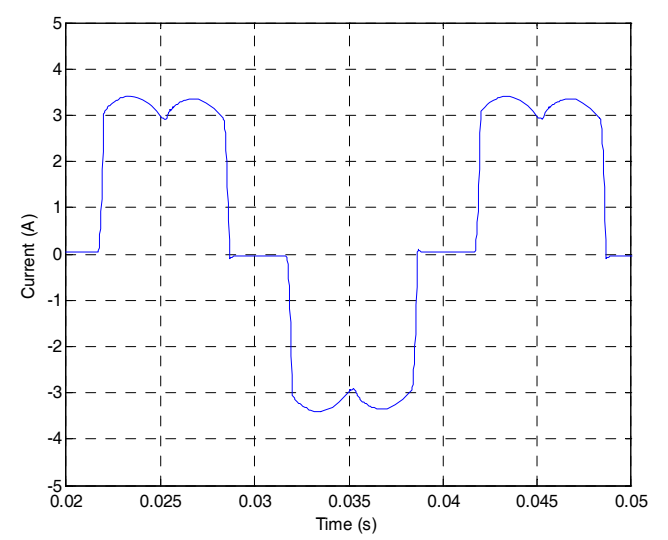

(a) Source current $i_{\mathrm{s} 1}$

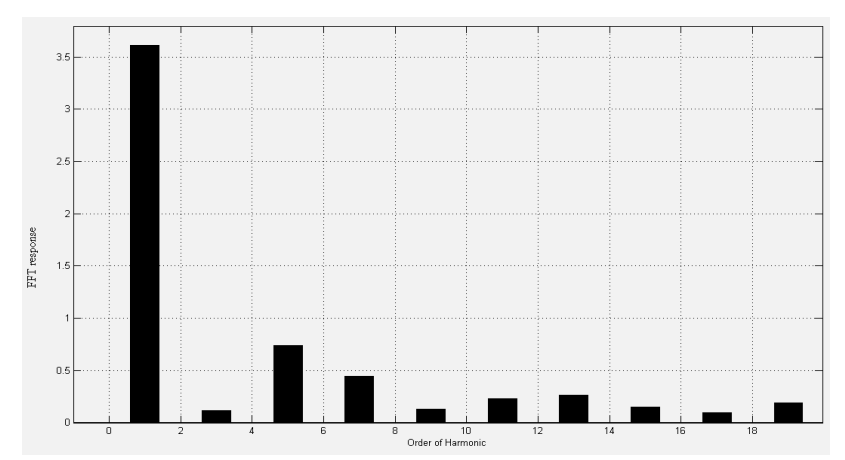

(b) Current FFT without injection. show a discontinuity in source current $i_{1}$ (Fig. 1). Then the three-phase diode bridge rectifier suffers from relatively high total harmonic distortion (THD) of the input currents; about $29,11 \%$ for the presented circuit in Fig. 1. We can reduce this distortion using the third harmonic current injection method. The THD is defined as the root mean square (RMS) value of the total harmonics of the signal, divided by the RMS value of its fundamental signal. For the currents, the $\mathrm{THD}_{\mathrm{I}}$ is defined by:

$$
\begin{gathered}
T H D_{I} \%=\frac{\sqrt{\sum_{n=2}^{\infty} I_{n R M S}^{2}}}{I_{1 R M S}} \times 100 \% \\
\frac{\sqrt{I_{2 R M S}^{2}+I_{3 R M S}^{2}+\ldots+I_{n R M S}^{2}}}{I_{1 R M S}} \times 100 \%
\end{gathered}
$$

The general scheme of harmonic injection method is presented in Fig. 2. It shows a diode bridge rectifier that consists of six diodes, three of them rectify the positive wave and the last three ones rectify the negative wave. Two circuits are added, a current injection network and a current injection device. The first circuit produces an injected current ig characterized by a frequency three times the frequency of the source. In this paper the frequency of the current injection is $150 \mathrm{~Hz}$. The second circuit divides into three parts where every part will be injected to each of the input source phase.

Let's begun with the principles of the three phase PFC rectifier that uses a third harmonic current injection system.

\subsection{Principles of current injection}

The rectifier is supplied by a symmetric undistorted three-phase voltage system,

$$
\begin{gathered}
v_{1}=V_{m} \cdot \cos \left(\omega_{0} t\right) \\
v_{2}=V_{m} \cdot \cos \left(\omega_{0} t-\frac{2 \pi}{3}\right) \\
v_{3}=V_{m} \cdot \cos \left(\omega_{0} t+\frac{2 \pi}{3}\right)
\end{gathered}
$$

The diode state functions $\mathrm{D}_{k}$ for $k \in\{1,2,3,4,5,6\}$ is defined so that $\mathrm{D}_{k}=1$ if the diode indexed with $\mathrm{k}$ conducts, and $\mathrm{D}_{k}=0$ if the diode is blocked. After that, let us express the input currents of the rectifier shown in Fig. 2, applying the diode state functions. In an expanded form, the input currents are:

$$
\begin{aligned}
& i_{1}\left(\omega_{0} t\right)=\mathrm{D} 1\left(\omega_{0} t\right) \cdot i_{A}\left(\omega_{0} t\right)-\mathrm{D} 2\left(\omega_{0} t\right) \cdot i_{B}\left(\omega_{0} t\right)-i_{X 1}\left(\omega_{0} t\right) \\
& i_{2}\left(\omega_{0} t\right)=\mathrm{D} 3\left(\omega_{0} t\right) \cdot i_{A}\left(\omega_{0} t\right)-\mathrm{D} 4\left(\omega_{0} t\right) \cdot i_{B}\left(\omega_{0} t\right)-i_{X 2}\left(\omega_{0} t\right) \\
& i_{3}\left(\omega_{0} t\right)=\mathrm{D} 5\left(\omega_{0} t\right) \cdot i_{A}\left(\omega_{0} t\right)-\mathrm{D} 6\left(\omega_{0} t\right) \cdot i_{B}\left(\omega_{0} t\right)-i_{X 3}\left(\omega_{0} t\right)
\end{aligned}
$$

Fig. 1. Source current $i_{\mathrm{s} 1}$ simulation results 


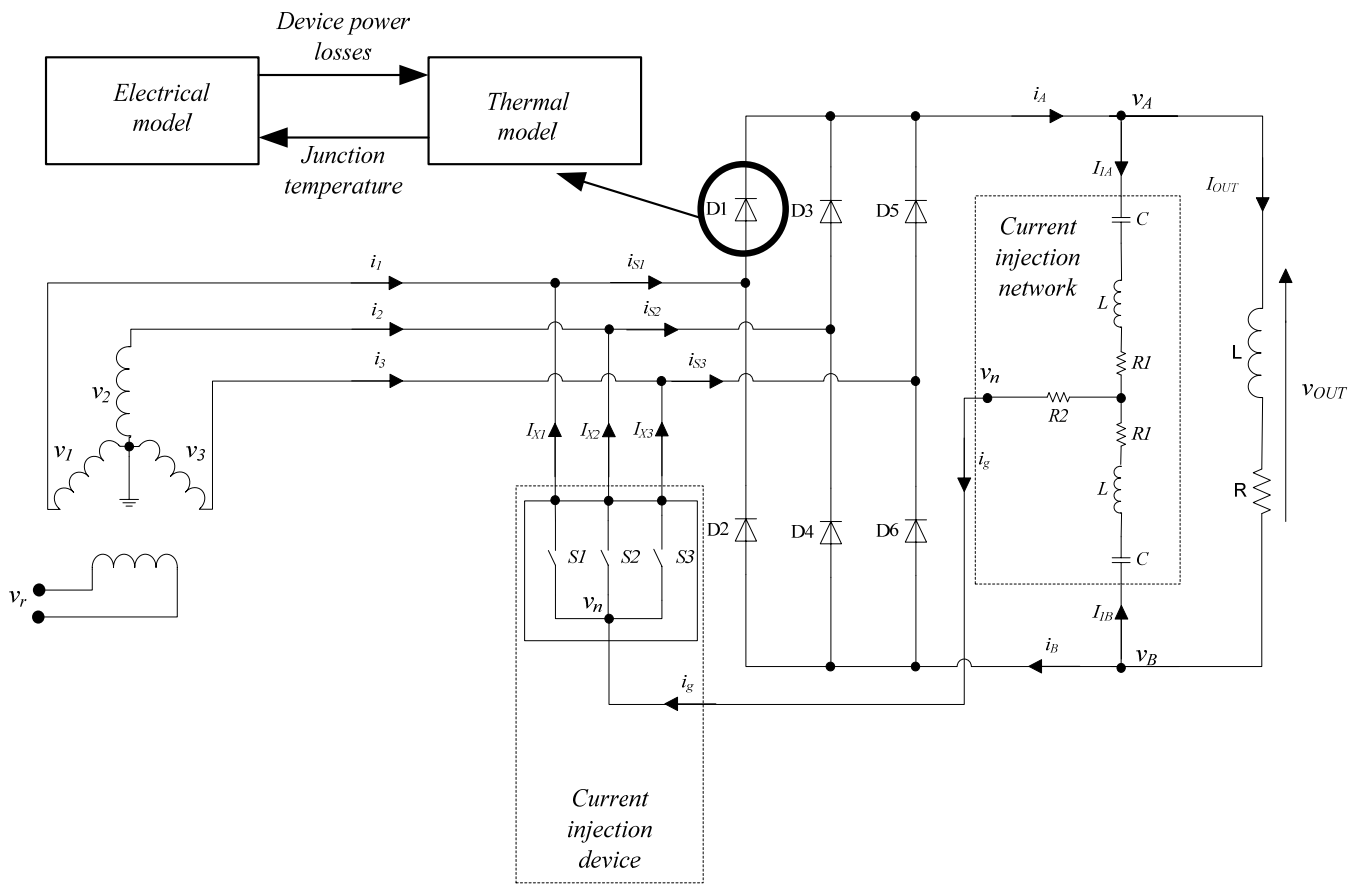

Fig. 2. Third harmonic injection schema

A reasonable requirement to be imposed on the input currents is that they should have the same waveforms, except for the displacement for one third of the line period,

$$
i_{1}\left(\omega_{0} t\right)=i_{2}\left(\omega_{0} t-\frac{2 \pi}{3}\right)=i_{3}\left(\omega_{0} t+\frac{2 \pi}{3}\right)
$$

The same phase displacement relation holds for the diode state functions of the odd-indexed diodes in the diode bridge:

$$
d_{1}\left(\omega_{0} t\right)=d_{3}\left(\omega_{0} t-\frac{2 \pi}{3}\right)=d_{5}\left(\omega_{0} t+\frac{2 \pi}{3}\right)
$$

As well as for the even-indexed diodes:

$$
d_{2}\left(\omega_{0} t\right)=d_{4}\left(\omega_{0} t-\frac{2 \pi}{3}\right)=d_{6}\left(\omega_{0} t+\frac{2 \pi}{3}\right)
$$

One way to satisfy the phase displacement constraint (8), having the diode state functions satisfying the same constraint as specified by (9) and (10), is to provide the injected currents $i_{X 1}, i_{X 2}$, and $i_{X 3}$ satisfying

$$
i_{X 1}\left(\omega_{0} t\right)=i_{X 2}\left(\omega_{0} t-\frac{2 \pi}{3}\right)=i_{X 3}\left(\omega_{0} t+\frac{2 \pi}{3}\right)
$$

And the diode bridge load currents $i_{A}$ and $i_{B}$ periodic with the period equal to one third of the line period,

$$
i_{A}\left(\omega_{0} t\right)=i_{A}\left(\omega_{0} t-\frac{2 \pi}{3}\right)=i_{A}\left(\omega_{0} t+\frac{2 \pi}{3}\right)
$$

and

$$
i_{B}\left(\omega_{0} t\right)=i_{B}\left(\omega_{0} t-\frac{2 \pi}{3}\right)=i_{B}\left(\omega_{0} t+\frac{2 \pi}{3}\right)
$$

It should be noted here that the fundamental frequency of the waveforms of $i_{A}$ and $i_{B}$ that satisfies (12) and (13) is the triple of the line frequency, $3 \omega_{0}$. For waveforms of the injected current $i_{X 1}, \quad i_{X 2}$, and $i_{X 3}$, only the phase displacement constraint is assumed, and the fundamental frequency of these currents can be the line frequency, like for the input currents $i_{1}, i_{2}$, and $i_{3}$. On the other hand, the phase displacement constraint can be satisfied in a special case that the injected currents are the same:

$$
i_{X 1}\left(\omega_{0} t\right)=i_{X 2}\left(\omega_{0} t\right)=i_{X 3}\left(\omega_{0} t\right)=i_{X}\left(\omega_{0} t\right)
$$

And in that case the injected currents have to be periodic with the fundamental frequency equal to the triple of the line frequency, $3 \omega_{0}$. This directly follows from the phase displacement constraint

$$
i_{X}\left(\omega_{0} t\right)=i_{X}\left(\omega_{0} t-\frac{2 \pi}{3}\right)=i_{X}\left(\omega_{0} t+\frac{2 \pi}{3}\right)
$$

\subsection{Current injection network}

To create the third harmonic current injection various methods was presented in bibliography [3-7]. In Fig. 2, we represent a tuned LC circuit as a current injection network. Two series of inductances and capacitors tuned at a specific resonant frequency creates a sinusoidal current. With a frequency of $3 \omega_{0}$, we use the Eq. (16) to calculate the value of both capacitors and inductors. The resistance R2 limits 
the injected current $i_{g}$ to satisfy (17) equation.

$$
\begin{aligned}
& F_{e}=\frac{1}{2 \pi \sqrt{L C}} \\
& i_{g}=1 / 2 I_{O U T}
\end{aligned}
$$

\subsection{Current injection device}

Various method of the current injection network was presented in bibliography [12-17]. Fig. 2 shows the, current injection network using a tuned LC circuit. It uses two inductances with two capacitors tuned to resonant frequency of $3^{*} \mathrm{Fe}(150 \mathrm{~Hz})$, the resistance limits the injected current.

Fig. 3 shows also the switching current injection device. It consists of three bidirectional switches. This bidirectional switch consists of a diode bridge and one controlled switch, being a MOSFET (IRF250) transistor in our application.

Fig. 4 illustrates the control circuit of the three switches. The six binary values that describe every intersection between the voltage levels of the input source is decoded by a matrix decoder that's activates the different switches based on the logic table (Table 1).

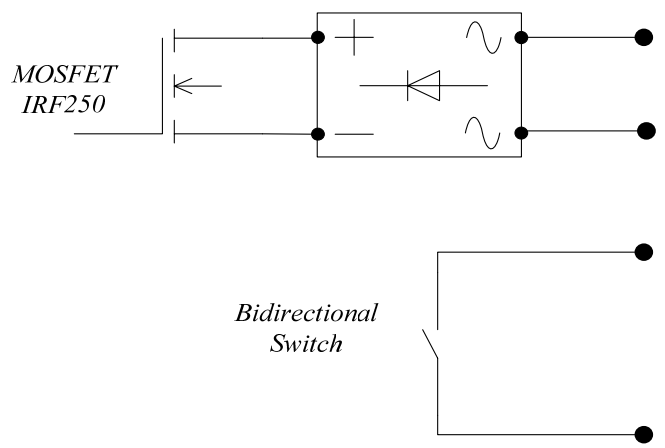

Fig. 3. Schema of bidirectional switch

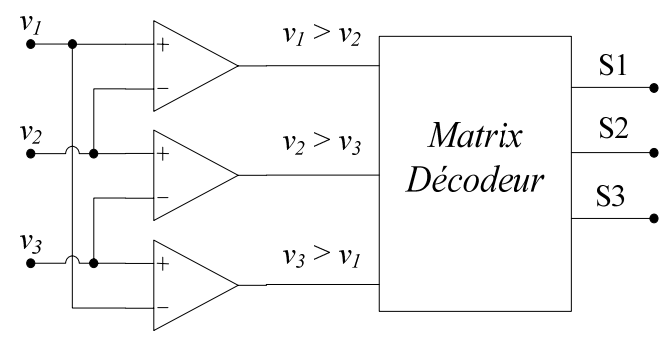

Fig. 4. Control circuit of the current injection device

Table 1. Logic of the matrix decoder

\begin{tabular}{c|c|c|c}
\hline $\mathrm{V}_{1}>\mathrm{V}_{2}$ & $\mathrm{~V}_{2}>\mathrm{V}_{3}$ & $\mathrm{~V}_{3}>\mathrm{V}_{1}$ & \\
\hline $\mathrm{A} 2$ & $\mathrm{~A} 1$ & $\mathrm{~A} 0$ & Output \\
\hline 0 & 0 & 1 & $\mathrm{~S} 1$ \\
\hline 0 & 1 & 0 & $\mathrm{~S} 3$ \\
\hline 0 & 1 & 1 & $\mathrm{~S} 2$ \\
\hline 1 & 0 & 0 & $\mathrm{~S} 2$ \\
\hline 1 & 0 & 1 & $\mathrm{~S} 3$ \\
\hline 1 & 1 & 0 & $\mathrm{~S} 1$ \\
\hline
\end{tabular}

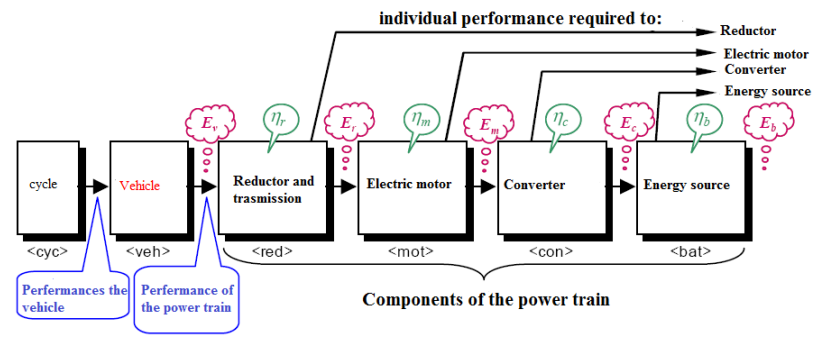

Fig. 5. Power train model

\section{Power Train Model}

The power train modeling is based on the energy model (Fig. 5). Indeed, it starts from the performances desired to arrive at the source of embarked energy. This last, is decomposable in two parts:

- The dynamic model of the Vehicle, it describes the total dynamic characterization of the electric chain of traction,

- The cycle of operation, it describes the dynamic characterization of the Vehicle.

The integrality of this dynamic model is carried out with MATLAB/Simulink.

The step of modeling of the Vehicle consists in subdividing the chain of electric traction in subsystem where each one converts the energy received with a corresponding loss. So the quantity of minimal energy that the batteries " $E_{b}$ must ensure" is known thanks to that necessary to the displacement of the vehicle "EV".

The following equation represents the basic structure of the model:

$$
E_{b}=\frac{E_{v}}{\eta_{r}\left(E_{v}\right) \eta_{m}\left(E_{r}\right) \eta_{c}\left(E_{m}\right) \eta_{b}\left(E_{c}\right)}
$$

Or $\eta$ : qualify the specific output each sub-system,

To optimize the vehicle power train, it makes sense to optimize the performance of each elementary block of the power train (Fig. 5). In this paper we are interested in optimizing the losses in the static converters in particular the rectifier providing the conversion of electrical energy in the vehicle. The idea is to minimize the harmonics on the entered bus of the rectifier which minimizes the joules losses and therefore maximize system yield.

\section{Electro-thermal Model of the Power Diode}

\subsection{State of the art}

When the power pulse durations are small, the evolution of the thermal impedance curves is very sensitive to duty 
cycle variations. In these conditions the temperature gradient inside the device is large especially in the silicon die. Moreover, in the case of a vertical power device, the electrical power is dissipated at the top of the silicon die (device active region). Heat flows from the top surface (S) mainly in a perpendicular direction (Fig. 6.a). So, a onedimensional heat flow may be considered for the silicon layer (Fig. 6.a)

Because most of the semiconductor device models are implemented in the circuit simulators, thermal circuit networks are the practical models for electro-thermal simulations. The literature proposes some approaches to construct thermal networks equivalent to a discretization of the heat Eq. [18-20]. For example, the Finite Element Method (FEM) and the Finite Difference Method (FDM) are proposed. In the case of vertical power devices, where the thickness $L_{S}$ is small compared to other dimensions, it is commonly considered that heat is generated at the top surface of silicon and it flows uniformly along the $\mathrm{x}$-axis (perpendicular to the silicon surface). So, the top surface $(A)$ is considered to be a geometrical boundary of the device at $x=0$, where the input power $P_{0}(\mathrm{t})$ is assumed to be uniformly dissipated. In our case, the (FEM) technique has been chosen to develop the thermal model of the structure. In this study, convection and radiation are assumed negligible. The thermal model of the silicon material can be represented by the equivalent electrical circuit (Fig. 6.b).

where $[21,22] C_{1}=\frac{\rho c v_{S} A L_{S}}{2(n-1)} ; C_{2}=-\frac{\rho c v_{S} A L_{S}}{6(n-1)}$

and $R=\frac{L_{S}}{k_{S} A(n-1)}$

$n$ : is the number of nodes in the material model, $k_{S}$ :

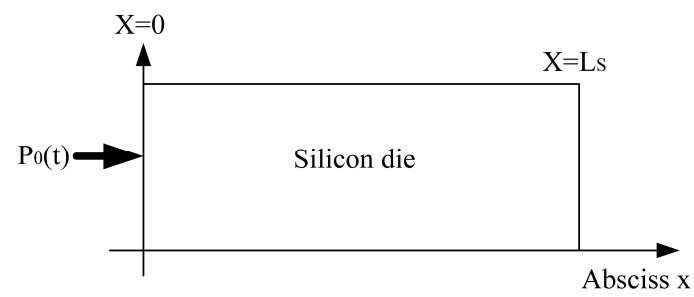

(a)

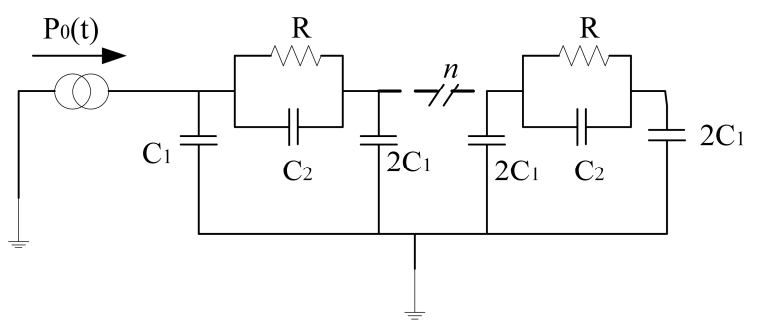

(b)

Fig. 6. (a) Unidimensional semiconductor die representation considered for the thermal modeling; (b) 1D FEM thermal model of the silicon material. thermal conductivity and $\rho c v_{S}$ : thermal capacity.

\subsection{Equivalent thermal model of a power diode package}

Most discrete power diode (without electrical insulator between chip and case) comprise three main components: a silicon die, a die attach and a spreader. This power diode (BYT 12P-1000 (12 A/1000V) (TO220 package)) [23, 24] contains three layers of different materials; is characterized by its thermal capacity $\rho c_{V i}$ its thickness $L_{i}$ and its thermal conductivity $k_{i}$ (Fig. 7). Table 2 shows the properties of the materials in the various layers of the power diode. These values are provided by the manufacturer and/or by the literatures $[23,25]$.

The last expressions can be used to develop the advanced 1D thermal model which takes into account the

Table 2. Different thermal parameters of power diode.

\begin{tabular}{c|c|c|c}
\hline Material & $\mathrm{L}_{\mathrm{i}}(\mathrm{mm})$ & $\mathrm{k}_{\mathrm{i}}(\mathrm{W} / \mathrm{mK})$ & $\rho \mathrm{c}_{\mathrm{Vi}}\left(\mathrm{J} / \mathrm{Kcm}^{3}\right)$ \\
\hline Silicon & 0.4 & 134 & 1.7 \\
\hline Solder & 0.01 & 35 & 1.3 \\
\hline Heat spreader & 1.23 & 143 & 3.5 \\
\hline Thermal grease & 0.1 & 1 & 2.1 \\
\hline
\end{tabular}

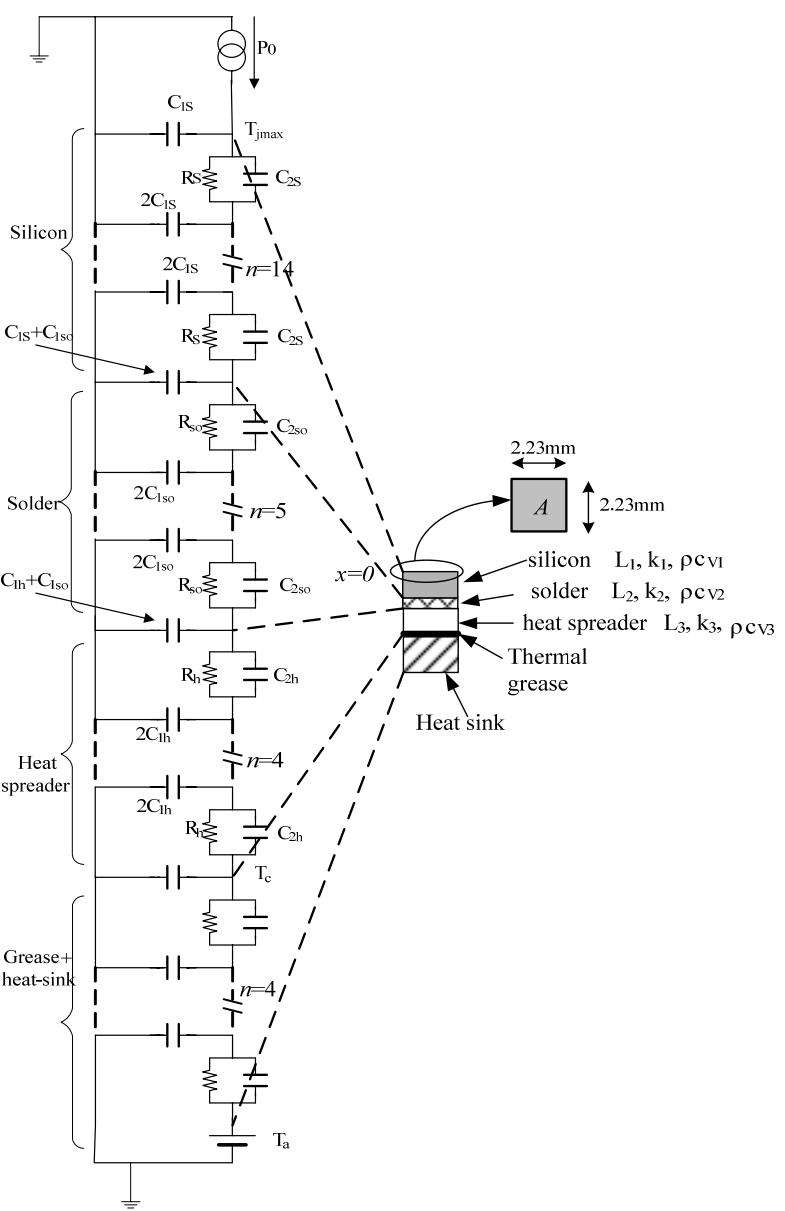

Fig. 7. Structure and 1D thermal model of the power diode 
lateral heat spreading in the power diode. The proposed thermal model is not only function of the geometric parameters of the studied structure but depends on dissipated power and boundary conditions. The 1D thermal model for the power diode (including package and heat sink) is shown in Fig. 7. Each layer is modeled by 1D Finite Element Method. The chosen model-orders are sufficient to predict the peak junction temperature inside the device under large power surge conditions. The use of silicon thermal model order greater than 14 for example, does not participate significantly to the improvement of the thermal response accuracy [22] (14 for silicon, 5 for solder, 4 for heat spreader and 4 for grease and heat-sink, for example).

The thermal model in power diode is implemented in MATLAB simulator [26] in order to estimate diode junction temperature and case temperature.

\subsection{Validation of transient thermal model of the power diode}

The experimental estimation of the diode junction temperature is based on the measure of electric thermosensitive parameters. It is considered to measure the drop voltage in the on-state $\left(V_{d}\right)$ during the heating phase of the device [27]. The electric circuit used for this experiment is shown in Fig. 8. Indeed, when the switch $(S W)$ is $O N$, an important current (heating phase) will flow in the diode. The switch $(S W)$ commute to the position $O F F$ the diode is biased with a very low current value (few mill Amperes) and the drop voltage across the diode $\left(V_{d}\right)$ is enregistred. So, every 15 seconds, the switch $(S W)$ will be open for a few microseconds and then closed again. During this time the drop voltage will be recorded using an oscilloscope memory. The power diode will be fixed to a heat sink [2829]. A thermo-resistance is placed in a hole performed in the heat sink, at the interface with the case and the case temperature is measured by a thermo-resistance. An essential characteristic, needed to estimate the junction temperature in the power diode, is the drop voltage calibration curve. A heat flow generator controls the diode temperature which is supposed to be homogeneous in the structure.

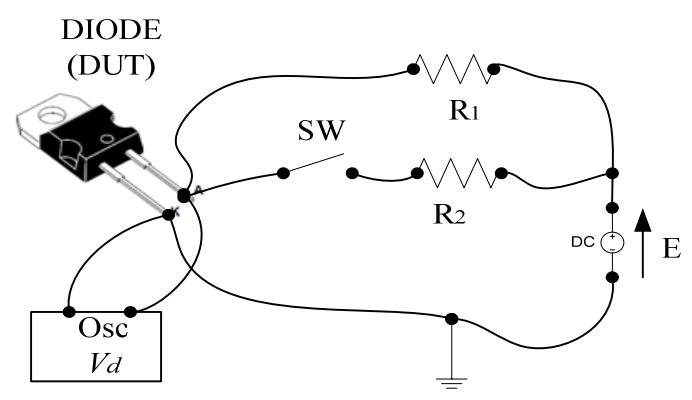

Fig. 8. Electric circuit used for the measure of the diode drop voltage during the heating phase

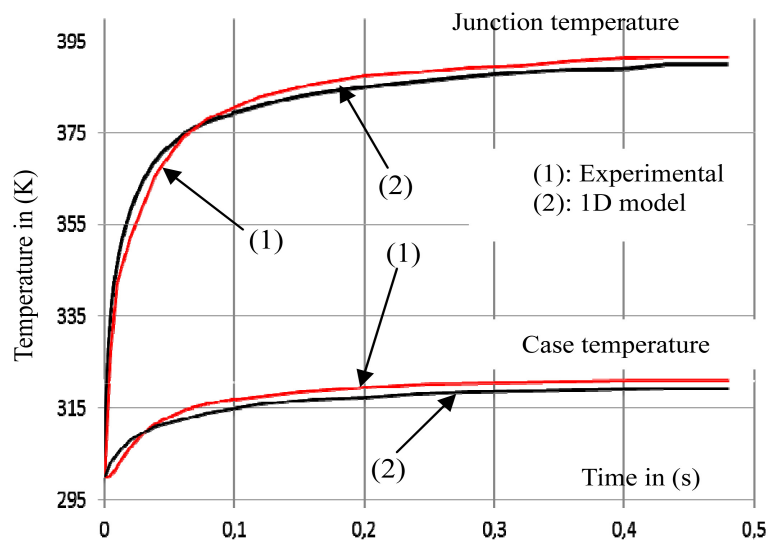

Fig. 9. Evolutions of the junction temperature and case temperature, in the DIODE, obtained by experimental and by the $1 \mathrm{D}$ thermal models. (dissipated power in the diode $=20 \mathrm{~W}$ and $\mathrm{R}_{\mathrm{rad}}=$ $0,42 \mathrm{~K} / \mathrm{W})$.

To verify the accuracy of the $1 \mathrm{D}$ thermal model in the transient state, a power steps are dissipated in the diode.

Fig. 9 shows the transient thermal responses at the junction and at the case of the diode when dissipated power magnitude is equal to $20 \mathrm{~W}$ and the resistance radiator equal to $0,42 \mathrm{~K} / \mathrm{W}$. These results are obtained by the $1 \mathrm{D}$ model and the experimental results.

A good accuracy is noticed between the 1D and the experimental results. So, transient thermal behavior of the proposed model is correct and the introduced error is not important.

\subsection{Electric model of power diode}

In its linear zone, the static characteristics of the power DIODE can be modeled by a line of slope $1 / \mathrm{R}_{0}$ and $\mathrm{X}$ coordinate in the $\mathrm{V}_{0}$ threshold (Fig. 10).

We can, then, express the voltage drop at the boundaries of the power DIODE in the linear zone by:

$$
V_{d}=V_{0}+R_{0} I_{d}
$$

$V_{0}$ and $R_{0}$ can be expressed by the following Eqs. [30]:

$$
\begin{gathered}
V_{0}=V_{00}+\alpha T_{j} \\
R_{0}=R_{00}+\beta T_{j}
\end{gathered}
$$

where

$V_{00}$ represents the voltage threshold at $0^{\circ} \mathrm{C} ; R_{00}$ is the resistance at $0^{\circ} \mathrm{C} ; \alpha$ and $\beta$ are the sensitivity coefficients of the temperature and $\mathrm{T}_{\mathrm{j}}$ is the junction temperature of the power DIODE in ${ }^{\circ} \mathrm{C}$.

It is important to measure the $V_{d}$ (saturation voltage) and the current in the power DIODE $\left(I_{d}\right)$ at various junction temperatures (Fig. 11). At heating flow generator controls the device temperature and the temperature in the power DIODE which are supposed to be homogeneous. Because, 


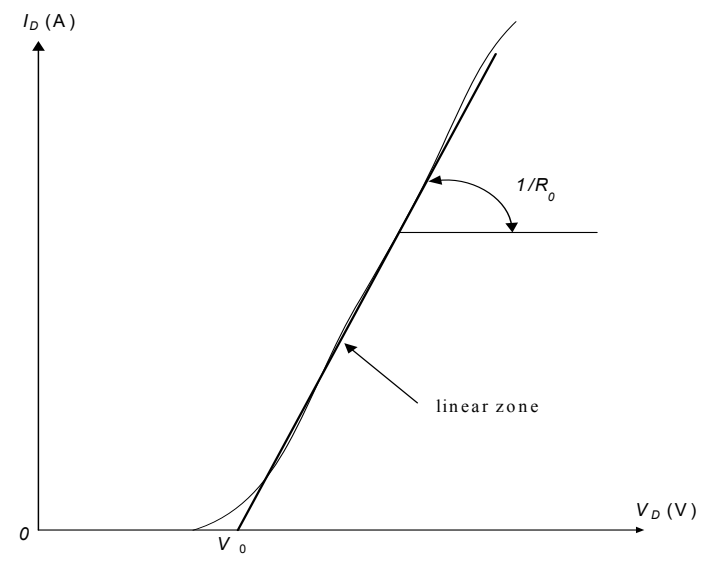

Fig. 10. Evaluation of the static characteristics in power DIODE

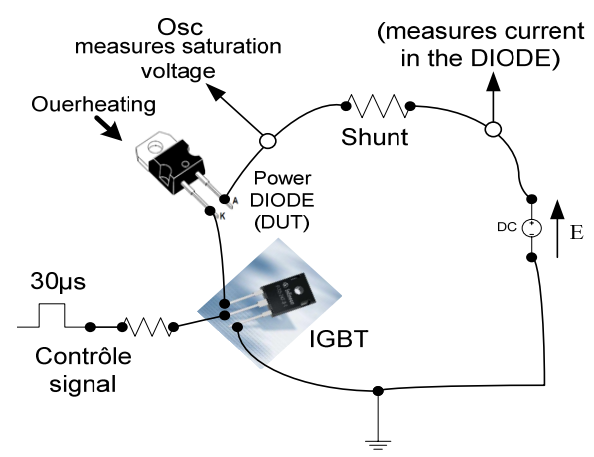

Fig. 11. Experimental circuit used for the measurement of the saturation voltage $\left(\mathrm{V}_{\mathrm{d}}\right)$ and the current in the power DIODE $\left(\mathrm{I}_{\mathrm{c}}\right)$ at various junction temperatures $\left(T_{j}\right)$.

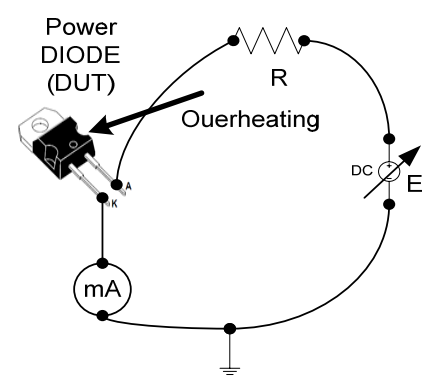

Fig. 12. Experimental circuit used for the measurement of the voltage $\left(\mathrm{V}_{0}\right)$ at various junction temperatures $\left(T_{\mathrm{j}}\right)$.

to avoid self heating of the power DIODE, it will be conductive for a short time (15 to $30 \mu \mathrm{s})$ through the IGBT. To measure the variation of the voltage $V_{0}$ at different junction temperatures, it is to apply a voltage across the power diode and detecting a low current in the component ( $5 \mathrm{~mA}$, for example). Indeed, it is by increasing the voltage $\left(V_{d}\right)$ until you see a small current in the milliamp (Fig. 12). Under these conditions it is noted that the voltage across the DIODE is equal to $V_{d}$.
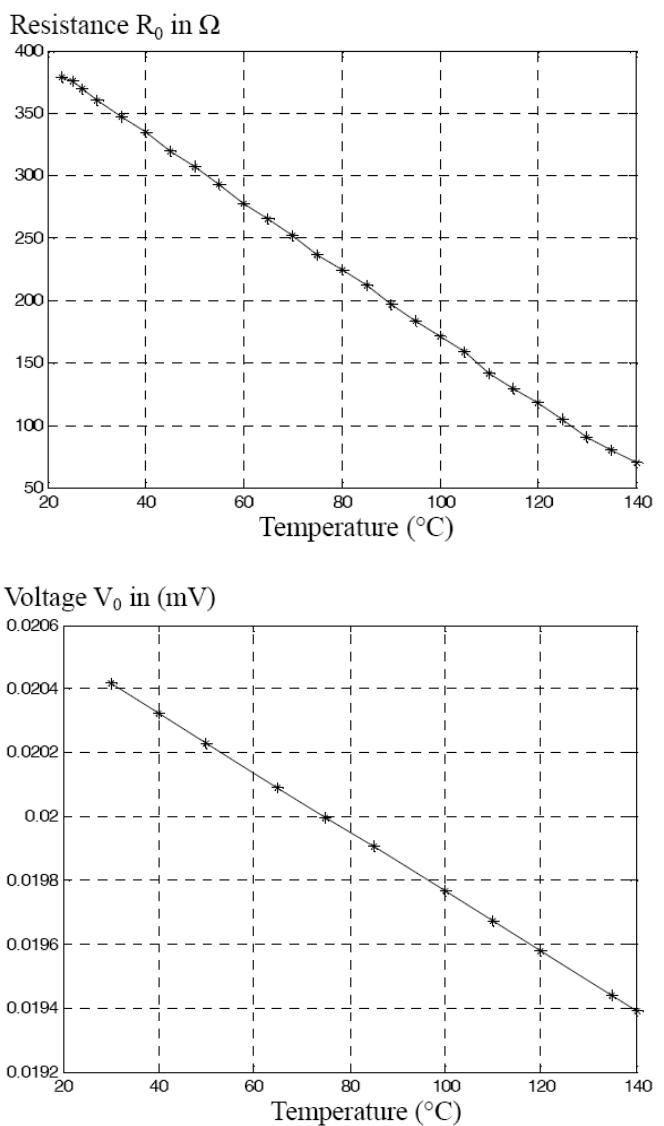

Fig. 13. Evaluations of the resistance $R_{0}$ and the voltage $V_{0}$ of the power DIODE obtained by experiments at various temperatures.

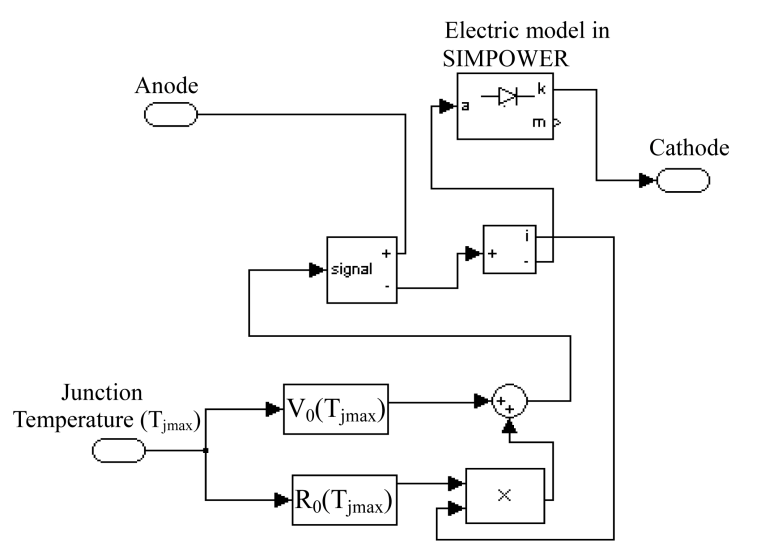

Fig. 14. Electro-thermal model of the power DIODE implemented in MATLAB.

Fig. 13 shows the evaluations of the resistance $R_{0}$ and the voltage $\mathrm{V}_{0}$ of the power DIODE at various temperatures obtained by experimental. As Fig. 13 illustrates, the resistance $R_{0}$ and the voltage $V_{0}$ can be approximated by the following simple polynomial function :

$$
\begin{aligned}
& R_{0}=-1,23 e^{-5} T_{j}+0,0209 \\
& V_{0}=-0,0027 T_{j}+0,4412
\end{aligned}
$$




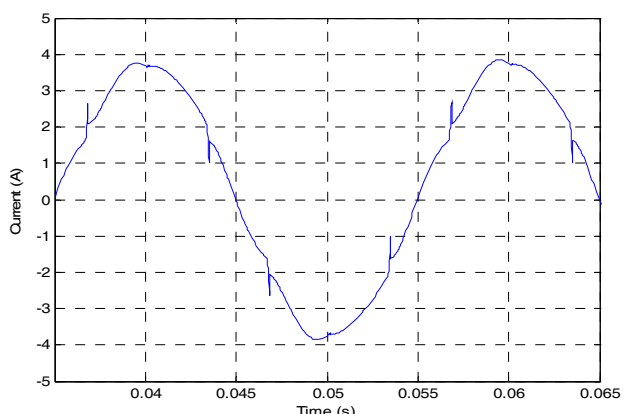

(a) Current source $i_{1}$

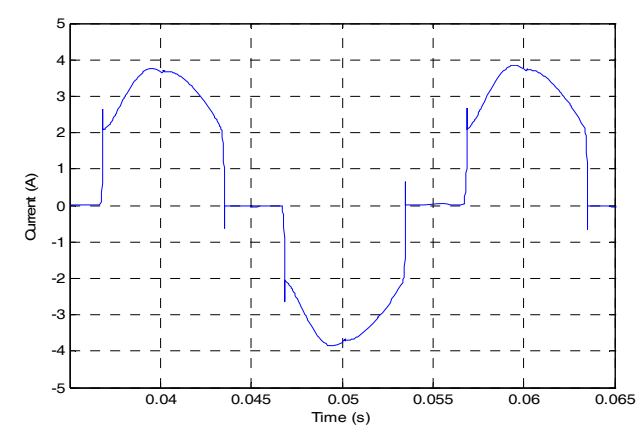

(b) Current source $i_{S 1}$

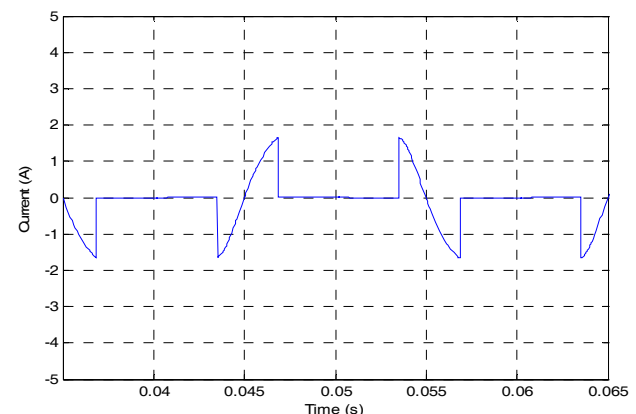

(c) Injected current $i_{X I}$

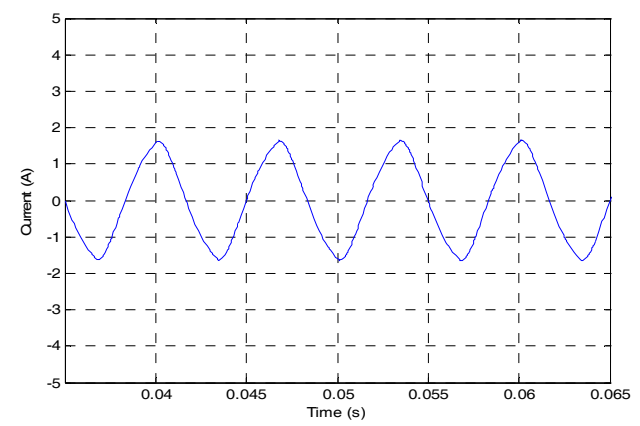

(d) Injected current $i_{g}$

Fig. 15. Simulation results

\subsection{Electro-thermal modeling of power diode}

Fig. 2 shows a diagram of an electro-thermal simulation technique of power DIODE. In Fig. 2, an electrical model is coupling with a thermal one. The instantaneous value of the device power loss is injected in to the thermal model in which the thermal characteristics of the module are defined. Then, the instantaneous device temperature is generated by the thermal model and the temperatures of the dependent device model parameters are determined via this instantaneous device temperature. These calculations are performed simultaneously using a circuit simulator. So, the device and the thermal models are essential components of the electro-thermal simulation.

Thus, the new electric power diode model becomes very dependent on the junction temperature. In this light, Fig. 14 shows the electro-thermal models of the power DIODE implemented in the MATLAB simulator.

\section{Simulation Results}

The rectifier simulation is implemented in the MATLAB simulator using the electro-thermal model power DIODEs. The ambient temperature is fixed surrounding at 306K. Fig. 15 shows the implemented and simulated circuit in the MATLAB simulator.

The speed of alternator gives a $50 \mathrm{~Hz}$ of source frequency; $\mathrm{L}$ and $\mathrm{C}$ must have values that verify resonant frequency of $3 \omega_{0}(150 \mathrm{~Hz})$. Two inductors of $60 \mathrm{mH}$ and

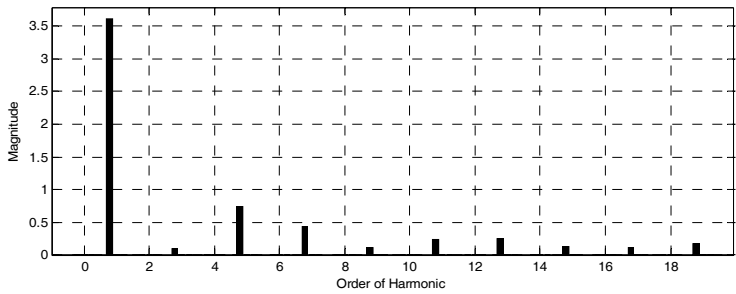

(a) Spectrum analysis of the input current $i_{1}$ without injection circuit

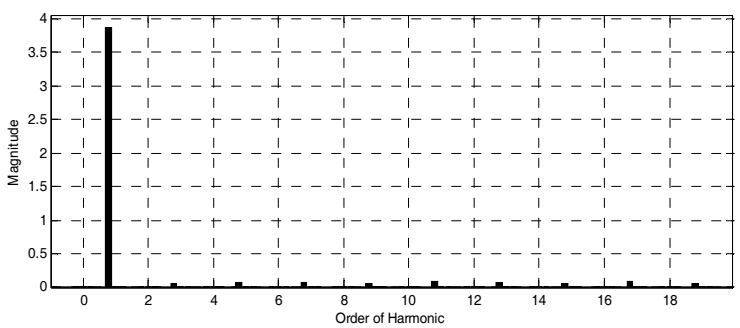

(b) Spectrum analysis of the input current $i_{1}$ with injection circuit

Fig. 16. Spectrum analysis result

capacitors of $18.75 \mu \mathrm{F}$ are used in the current injection network. R1 with the value of $10 \Omega$ represent the internal serial resistance of both inductor and capacitor. R2 is fixed at $45 \Omega$ to gives the maximum value of the injected current at $1.8 \mathrm{~A}$. The output charge includes a $10 \mathrm{mH}$ inductor and $65 \Omega$ power resistance

The simulation results are presented in Fig. 15. The 
injected current $i_{g}$ in Fig. 15.d have a sinusoidal form and present a triple of line frequency. The input current $i_{S I}$ of the rectifier bridge (Fig. 15.b) present a discontinuity when the phase voltage $v_{1}$ is neither maximal nor minimal relative to other phases; The bidirectional switches conduct at this time a part of $i_{g}$ current ( $i_{X I}$ Fig. 15.a). As result, the THD of the source line current $i_{l}$ (Fig. 15.a) is lower using the PFC method. From Fig. 15.a, we can conclude that there is a significant improvement on the input current waveform of the rectifier (Fig.1.a).

Expected value of the input current THD for the rectifier applying current injection network is equal to $4.2 \%$, which is about $25 \%$ less than the system without injection circuit. The rectifier applying current injection network is less sensitive on the input voltage distortion, since better filtering of harmonic components at even triples of the line frequency is provided. Total harmonic distortions of the input currents are presented in Fig. 16.

Fig. 17 shows the temperature variation of the power diode junction obtained by classical rectifier and PFCVF one. In the PFCVF simulation two different models have been used: with the electro-thermal model and with the electrical model.

It is clear that the power diode junction temperature obtained by PFCVF is lower than that obtained by the classical rectifier. For example, at a time equal to $0.1 \mathrm{~s}$, the junction temperature of power diode obtained by PFCVF rectifier is equal to $320 \mathrm{~K}$ whereas the diode junction temperature obtained by classical PFC is equal to $340 \mathrm{~K}$. It proves that the use of the PFCVF rectifier reduces the losses in the semiconductors switches. The PFCVF rectifier can be used for a very high power application which needs low stress on power devices as diodes.

The electric simulation is carried out at $33^{\circ} \mathrm{C}$. In that, at time equal to $0,15 \mathrm{~s}$, it is noticed that taking into consideration the variation of the static charactrestics of the

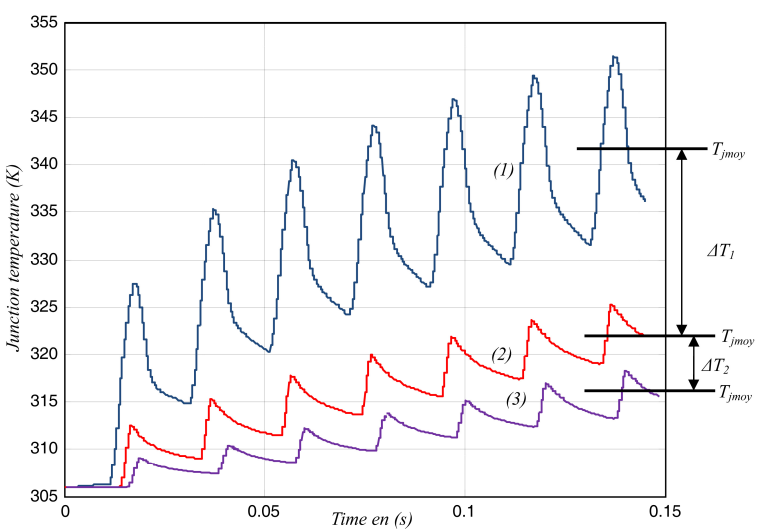

Fig. 17. Variation of the power diode junction obtained by classical rectifier and PFCVF: (1) obtained by the classical rectifier with electro-thermal model; (2) obtained by the PFCVF with electro-thermal model; (3) obtained by the PFCVF with electric model). device according to the junction temperature allows for a temperature correction of $27^{\circ} \mathrm{K}$ at the DIODE junction temperature.

The harmonics generated by the converter produce excessive losses on the rectifier diodes. The thermal model shows the improvement made by the PFC on the losses. In addition, the thermal model is a simple solution that estimates the junction temperature in real time in order to size the cooling system. In conclusion, Fig. 17 expresses a double validation. Initially, the curves 1 and 3 show the importance of the thermal model. Indeed, if one ignores the temperature effect on the power diode static characteristic (slope $1 / \mathrm{R}_{0}$ and $\mathrm{X}$-coordinate in the $\mathrm{V}_{0}$ threshold) the junction temperature will be underestimated $\left(\Delta \mathrm{T}_{2}=8^{\circ} \mathrm{K}\right)$ this involves particular design errors and especially in the radiator calculation. Secondly the developed electro-thermal model shows the interest of the injection technique; the curves 1 and 2 indicate the losses minimization $\left(\Delta \mathrm{T}_{1}=\right.$ $\left.22^{\circ} \mathrm{K}\right)$.

\section{Experimental Evaluation}

To verify the analytically obtained results a $1 \mathrm{~kW}$ rectifier is built Fig. 18. A synchronous machine is used as

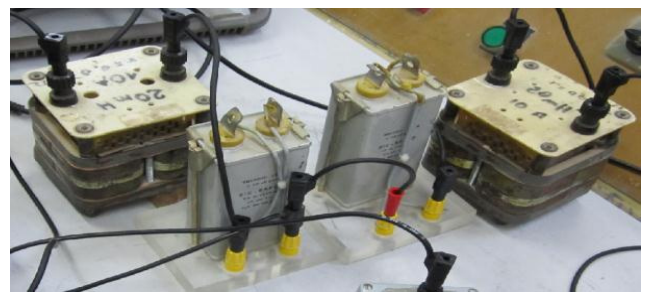

(a) LC current injection network

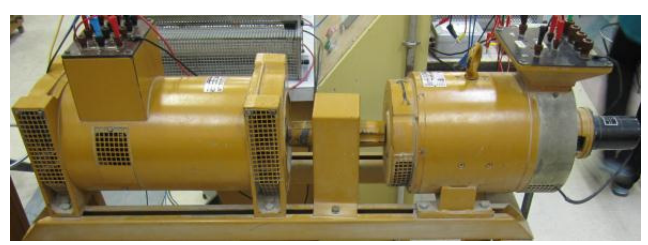

(b) Synchronous alternator coupled with a DC motor

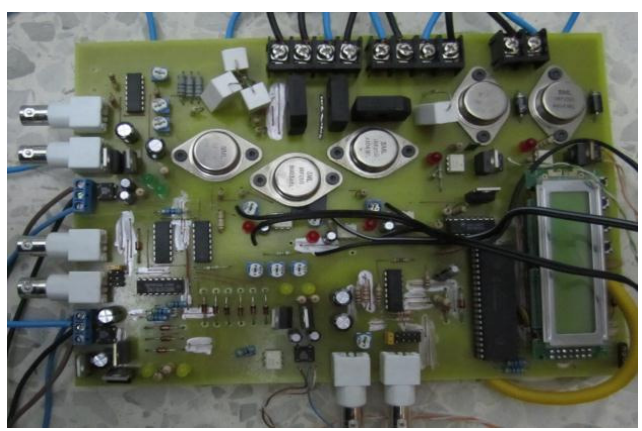

(c) Switching Current Injection Device

Fig. 18. Experimental circuit 


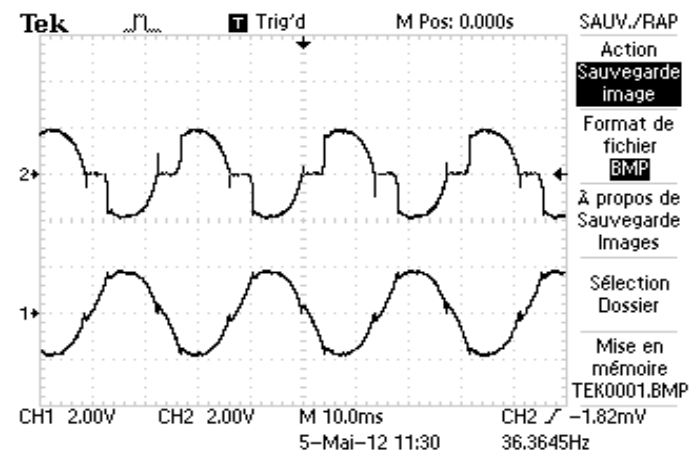

(a) Current source $i_{S 1}$ and $i_{1}$ using injection circuit

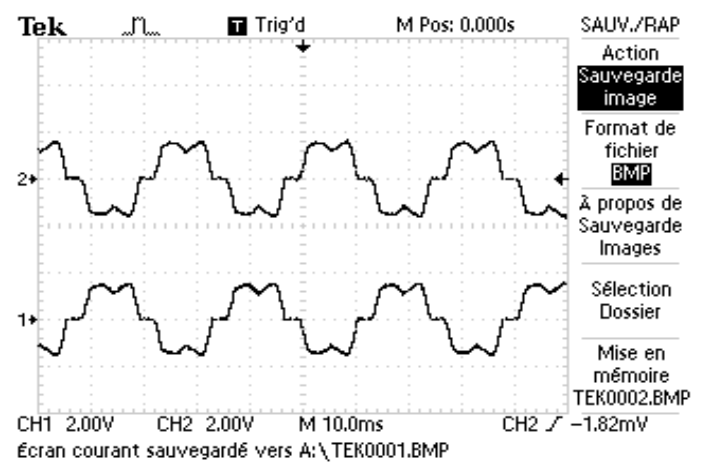

(b) Current source $i_{1}$ without injection circuit

Fig. 19. Current results

an alternator to create the three phase voltage system. The alternator is driven by a controlled DC motor to allow us to control the speed and then the output signal frequency.

The output voltage can be adjusted using a rheostat cabled in serial way with excitation source $v_{r}$. The current injection network shown in Fig. 18.a uses two $20 \mathrm{mH}$ inductor and two $100 \mu \mathrm{F}$ capacitor; the frequency of the resonant circuit is $112 \mathrm{~Hz}$, then we have to use a frequency of $37 \mathrm{~Hz}$ as a voltage source.

The output voltage is fixed to $100 \mathrm{~V}$; a $42 \Omega$ power resistor is used as a charging system and consume about $4 \mathrm{~A}$ of output current.

$i_{1}$ waveform and $i_{S I}$ are presented in Fig. 19; Waveform $i_{1}$ corresponding to the current with injection Fig. 19.a is less polluted by harmonics then the $i_{l}$ waveform without injection Fig. 19.b.

The electro-thermal model developed in section IV validates the injection technique on the rectifier. In fact with a simple electro-thermal model we are able to estimate the junction temperature in real time as well as the static characteristics of each power diode allowing closer results to the practice in the design of power systems in particular the electric vehicles application.

\section{Conclusion}

In this paper, we presented an electro-thermal model of a power system based on a new developed modelling methodology. The demonstrator is a PFC rectifier that uses a variable frequency source for electric vehicle application.

The found results from the measurements show a good arrangement compared to those obtained by mines of simulation, therefore showing the exactitude of the proposed electro-thermal model. It can be used to calculate the semiconductor losses at any output current waveform as long as a usual switching frequency (causing an insignificant current ripple) can be assumed.

By adopting the PFCVF strategy, the THD value is reduced by more than $50 \%$. The thermal model developed shows the minimization of losses in rectifiers. Indeed, the diode junction temperature $\left(\mathrm{T}_{\text {jmoy }}\right)$ value is decreased of $\Delta \mathrm{T}_{2}=22^{\circ} \mathrm{K}$ (from $340 \mathrm{~K}$ to $318 \mathrm{~K}$ ). The experimental results highlight the effectiveness of the proposed design. The proposed model is suitable for multiphysics traction drive simulations which can be used for predicting cooling system requests in EVs.

\section{Appendix}

Induction Motor Parameters

\begin{tabular}{c|c}
\hline Designation & Value \\
\hline Rated power (kW) & 4,5 \\
\hline Rated voltage (Volt) & $220 \Delta 380 \mathrm{Y}$ \\
\hline Rated current (Amp) & $19 \Delta 11 \mathrm{Y}$ \\
\hline Rated frequency (Hz) & 50 \\
\hline Rated speed (rpm) & 1395 \\
\hline Number of poles & 4 \\
\hline
\end{tabular}

\section{References}

[1] M. Ghariani and al, "Sliding mode control and neurofuzzy network observer for induction motor in EVs applications," Int. J. Electric and Hybrid Vehicles, Vol. 3, No. 1, 2011, pp. 20-46.

[2] F. Wang and B. Zhuo, "Regenerative braking strategy for hybrid electric vehicles based on regenerative torque optimization control," JAUTO654, Proc. IMechE vol. 222 Part D, January 2008 pp. 499-513.

[3] C. H. Chen and M. Y. Cheng, "Design and implementation of a high-performance bidirectional DC/ AC converter for advanced EVs/HEVs," IEE Proc.Electr. Power Appl., pp. 140-148, vol. 153, no. 1, January 2006.

[4] P. Pejovic, J. W. Kolar, and Y. Nishida "Bidirectional Ac-Dc Converter for Regenerative Braking," 16th International Symposium On Power Electronics - Ee 2011, Novi Sad, Republic Of Serbia, October 26th 28th, 2011

[5] M. Ghariani, A. Ltifi, I. Ben Salah, M. Ayadi and R. Neji "New Sliding-Mode Observer for Induction 
Machine in Electric Propulsion Applications," International Review on Modelling and Simulations, vol. 3, no. 4, August 2010, pp 493-501.

[6] C. Z. Liaw, D. M. Whaley, W. L. Soong, and N. Ertugrul, "Investigation of Inverterless Control of Interior Permanent-Magnet Alternators," IEEE Transactions on Industry Applications, pp. 536-544, vol. 42, no. 2, April 2006.

[7] W. L. Soong, and N. Ertugrul, "Inverterless HighPower Interior Permanent-Magnet Automotive Alternator," IEEE Transactions on Industry Applications, vol. 40, no. 4, Aug 2004, pp. 1083-1091.

[8] R. Ghosh and G. Narayanan, "Control of Three-Phase, Four-Wire PWM Rectifier," IEEE Transactions on Power Electronics, vol. 23, no. 1, January 2008, pp. 96-106.

[9] J. Sastry, O. Ojo and Z. Wu, "High Performance Control of a Boost AC-DC PWM Rectifier-Induction Generator System,” IAS 2005, pp. 1007-1014.

[10] M. Ayadi, El M'Barki, M. Ghariani and R. Neji “A Comparison of PWM Strategies for Multilevel Cascaded and Classical Inverters Applied to the Vectorial Control of Asynchronous Machine," International Review of Electrical Engineering, vol. 5, no. 5, October 2010, pp. 2106-2114

[11] J. I. Itoh and I. Ashida, "A Novel Three-Phase PFC Rectifier Using a Harmonic Current Injection Method," IEEE Transactions On Power Electronics, vol. 23, no. 2, March 2008.

[12] N. Mohan, "A Novel Approach to Minimize LineCurrent Harmonics in Interfacing Power Electronics Equipment with 3-Phase Utility Systems," IEEE Transactions on Power Delivery, vol. 8, no. 3, July 1993, pp. 1395-1401.

[13] P. Pejovic and Z. Janda, "An Analysis of ThreePhase Low-Harmonic Rectifiers Applying the ThirdHarmonic Current Injection," IEEE Transactions on Power Electronics, vol. 14, no. 3, May 1999, pp. 397407.

[14] A. Toumi, M. Ghariani, I. Ben Salah and R. Neji "Three-Phase PFC Rectifier Using a Switching Current Injection Device for Vehicle Power Train Applications," International Journal of Electrical Engineering and Transportation, vol. 6, no. 2, January 2010.

[15] P. B. Sánchez, S. H. Flores, “Three-Phase Power Factor Correction Circuit with Asymmetrical Output for Automobile Applications," 18th International Conference on Electronics Communications and Computers, pp. 154-159.

[16] Y. Li, F. C. Lee, J. Lai, and D. Boroyevich, “A Novel Three-phase Zero-Current-Transition and Quasi-ZeroVoltage-Transition (ZCT-QZVT) Inverter / Rectifier with Reduced Stresses on Devices and Components," IEEE 2000, pp. 1030-1036.

[17] M. GHARIANI, A. LTIFI, I. BEN SALAH, M.
AYADI, R. NEJI "New sliding-mode observer for i nduction machine in electric propulsion applicatio ns"; Praise Worthy Prize, International Review on Modelling and Simulations (IREMOS), Vol. 3, N. 4, August 2010, pp. 493-501.

[18] Ammous A., Allard B., Morel H., "Transient temperature measurements and modeling of IGBT's under short circuit", IEEE Transaction Power Electronic, vol. $13 \mathrm{n}^{\circ}$ 1, 1998, p. 12-25.

[19] Farjah E., Scheffer Ch., Perret R., "Experimental Thermal Parameter Extraction Using Non-Destructive Tests", EPE, 1995, Sevilla, p. 1.245-1.248.

[20] Ludwig M., Gaedke A., Slattery O., Flannery J., Cian Mathuna S., "Characterisation of Cooling Curve for Power Device Die Attach Using a Transient Cooling Curve Measurement”, 0-7803-5692-6/00/\$10.00 (c) 2000 IEEE, p. 1612-1617.

[21] H.J. Tzer, L. Vu-Quoc, "A rational formulation of thermal circuit models for electrothermal simulation - Part I: Finite element method", IEEE Trans. Circuits Syst. — I: Fund. Theory Appl. 43 (9) (1996) 721-732.

[22] A. Ammous, "Choosing a thermal model for electrothermal simulation of power semiconductor devices", IEEE Trans. Power Electron. 14 (2) (1999) 300-307.

[23] Data sheet catalog. This datasheet has been download from: www.datasheetcatalog.com.

[24] Hatem Garrab, Bruno Allard, Hervé Morel, Member, Kaiçar Ammous, Sami Ghedira, Adel Amimi, Kamel Besbes, and Jean-Michel Guichon., "On the Extraction of PiN Diode Design Parameters for Validation of Integrated Power Converter Design", IEEE transaction on power electronics, vol. 20, $\mathrm{n}^{\circ} 3$, MAY 2005, p. $660-670$.

[25] Moez Ayadi, Mohamed Amine Fakhfakh, Moez Ghariani and Rafik Nej., "Electrothermal modeling of hybrid power", Microelectronics International, vol. 27, $\mathrm{n}^{\circ} 3,2010$, p. 170-177.

[26] MATLAB., 6p5 june 18, 2002.

[27] H. Bellaj, J. M. Dorkel, P. Tounsi, and Ph. Leturcq, "Validity and limits of the junction temperature concept for integrated power devices", THERMINIC'99, Rome, Italie, 1999.

[28] Moez Ayadi, Sihem Bouguezzi, Moez Ghariani, and Rafik Neji, "Experimental Investigations for Thermal Mutual Evaluation in Multi-Chip Modules", Journal of Power Electronics, Vol. 14, No. 6, November 2014, pp. 1345-1356.

[29] Kihyun Lee, Yongsug Suh, Yongcheol Kang, "Loss Analysis and Comparison of High Power Semiconductor Devices in 5MW PMSG MV Wind Turbine Systems", Journal of Power Electronics, Vol. 15, No. 5, September 2015, pp. 1380-1391.

[30] SCHAEFFER C. "Analyse des comportement électriques et thermique des interrupteurs de puissance 
IGBT à technologie hybride" thèse de doctorat de l'Institut Nationale Polytechnique de Grenoble, 30 Janvier 1992.

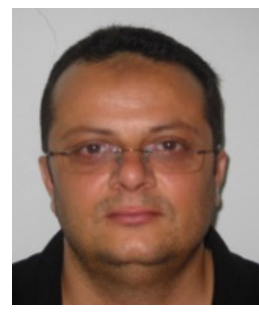

Moez Ayadi was born in Sfax, Tunisia, in 1973. He received the B.Sc. degree in electrical engineering from the National School of Engineers of Sfax, in 1999, the M.Sc. degree in electrical engineering from the National School of Engineers of Sfax, in 2000, the Ph.D. degree in electrical engineering from National School of Engineers of Sfax, in 2005, and HDR degree in electrical engineering from National School of Engineers of Sfax, in 2010. After receiving the HDR degree, he joined the Department of Electrical Engineering in School National of Electronic and Communication of Sfax (ENET'com), University of Sfax, Tunisia, where he is an Professor.

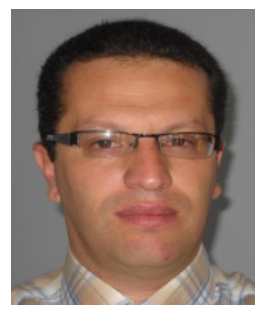

Moez Ghariani was born in Sfax, Tunisia, in 1971. He received the B.Sc. degree in electrical engineering from the National School of Engineers of Sfax, in 1996, the M.Sc. degree in electrical engineering from the National School of Engineers of Sfax, in 1997, and the Ph.D. degree in electrical engineering from National School of Engineers of Sfax, in 2003, and HDR degree in electrical engineering from National School of Engineers of Sfax, in 2010. After receiving the HDR degree, he joined the Department of Electrical Engineering in School National of Electronic and Communication of Sfax (ENET'com), University of Sfax, Tunisia, where he is an Professor.

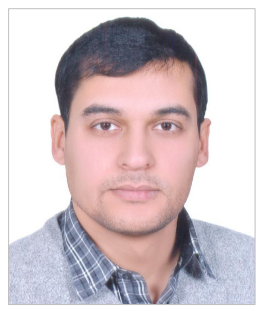

Amine Toumi was born in Sfax (Tunisia) in 1980. He received his electric Engineering Diploma and the Master degree in electronics from the Ecole Nationale d'Ingénieurs de Sfax Tunisia at 2005 and 2006 respectively. $\mathrm{He}$ is a member of Laboratory of Electronic and Information Technology Sfax (LETI). He is currently reading for a $\mathrm{Ph} \mathrm{D}$ degree in the performance improvement of electric vehicle. 